\title{
OPTIMIZATION OF THE SPARE PART STOCKS FOR THE PANDUR CZ ARMOURED VEHICLE
}

\author{
Jaromir MARES, Petr KRIZEK, Daniel ZLATNIK \\ University of Defence, Brno, Czech Republic \\ jaromir.mares@unob.cz; krizekp@razdva.cz; DanielZlatnik@seznam.cz
}

\begin{abstract}
The paper deals with the optimal solution of the proposal of spare part stocks for the PANDUR armoured vehicle operated in the Army of the Czech Republic. The aim of the paper is to propose an optimal amount of spare part stocks according to their categorization from the viewpoint of the purpose of consumption, delivery time and expected operation. The solution is based on comparing the actual spare part consumption and the normative consumption. The actual consumption is considered for the entire time of use in the Army of the Czech Republic. For the purposes of the submitted article the brainstorming techniques and the integrated environment of the MATLAB program have been used in addition of basic methods.
\end{abstract}

Keywords: stocks of spare parts normative consumption

\section{Introduction}

The issues related to the more efficient spare part supply and the amount of supply spare part stocks on wheels in missions and operations are a long-standing and burning issue. The fact that it is important and discussed in public is documented by a current offer of a special course and training at the Czech Technical University in Prague. This issue is also tackled abroad, as evidenced by the fact that the efficiency of supply is dealt with by the British supplier of spare parts for Peugeot, Citroen and Opel. He has changed over from a traditional method of supply to more efficient one, supported by the HUB and SPOKE method.

One of the main prerequisites for the operational success of troops is to ensure the operation of the main types of armament and equipment that are crucial from the viewpoint of enhancing the capabilities of combat units. The capability for sustainability within their own DOI: $10.1515 / \mathrm{kbo}-2018-0148$

(C) 2015. This work is licensed under the Creative Commons Attribution-NonCommercial-NoDerivatives 3.0 License. employment in operations is one of the major factors influencing the course of combat activities and the success of conduct of operations. Only a comprehensive, well sophisticated, efficient system with a broad link to adequately created armament and equipment reserves, stocks of spare parts, supply chains, trained and prepared personnel will enable the fulfilment of the prerequisites for the successful conduct of troop operations [1].

The necessary correction of processes and principles can be achieved by constant monitoring and evaluating the main trends within the actual employment of units in operations. Otherwise, the gradual reduction in the capabilities in the field of maintenance and repairs, which will negatively affect the overall capability of combat units and the army as a whole, will take place [2]. 
Within the current research, the submitted article is based on the facts that have been detected so far [3]; it focuses on the stockpiling of spare parts and their optimization for the PANDUR CZ vehicle based on the assessment of their long-term consumption. The PANDUR CZ vehicles were introduced into the ACR in 2009. When they are in use, the operational reliability, the total cost ratio concerning the spare part consumption and the cost of purchased services are monitored on a longterm basis. This is part of the life-cycle cost at the stage of their use [4].

\section{Current state of spare part provision}

The proper initial planning of logistic support is a prerequisite for the effective output of the maintenance and repair process. It is launched in a sufficient time to take full advantage of the limited time to provide the necessary assets, spare parts, the selection of the professional personnel and its training.

The logistic support system itself, including the setting of the spare part composition and the structure of units, is dependent on the fulfilment of a specified operational task and the conditions in the area of operations. The proposed block flow diagram of stock optimization shown in Figure 1 is an evaluation of the spare part consumption over a period of several years, its analysis and comparison with the normative consumption.

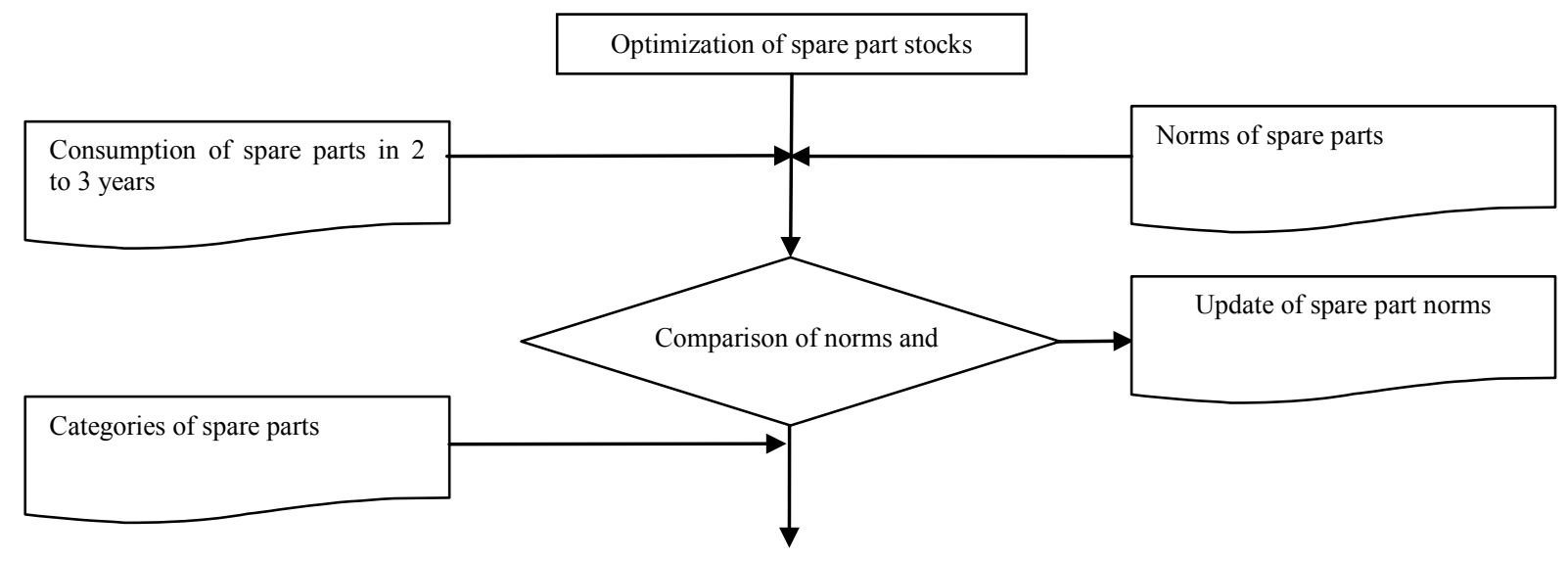

Figure 1 Block flow diagram of stock optimization [2]

Within the project entitled "Rearmed Army of the Czech Republic" with wheeled armoured vehicles, the mechanization workshop equipment, along with the PANDUR CZ vehicles, has also been acquired to carry out maintenance and repairs from the $1^{\text {st }}$ to the $3^{\text {rd }}$ level. The basic range of spare parts according to the normative consumption, the basic accompanying and operational documentation is in accordance $[5,6]$. The basic range of spare parts according to the normative consumption was acquired mainly due to its cataloguing. It should have served as a basic aid for planning and acquiring additional spare parts to ensure the serviceability of vehicles. It did not happen and spare parts were procured according to current needs, which extended the time of vehicle inoperability considerably.

During the operation time of the PANDUR vehicles (from 2010 to 2018), almost 8,000 pieces of spare parts were consumed within the technical maintenances and repairs, which represents approximately CZK 25.6 million. The reported consumption of spare parts has an increasing tendency due to the gradual termination of warranties for vehicles, as shown in Table 1. 
Table 1 Development of spare part consumption volume in finances

\begin{tabular}{l|c|c|c|c|c|c} 
Year & 2012 & 2013 & 2014 & 2015 & 2016 & 2017 \\
\hline $\begin{array}{l}\text { Price of spare parts } \\
\text { [mil. CZK] }\end{array}$ & 0.18 & 0.28 & 0.40 & 0.97 & 1.88 & 3.50
\end{tabular}

3. Used methods and examined material

During the research, it is necessary to conform to the principle that there is no need to realize savings at all costs, which could endanger the defence ability of the state.

Various methods of scientific research, both basic and special, have been used here. To determine the spare part stocks of combat vehicles, the Pareto (ABC) analysis has been successfully used [3, 7, 8, 9]. The possibilities of Microsoft Excel software and the MATLAB software support have been used in the article.

For logical inference of the acquired data, the brainstorming method was used, by means of which some extreme situations related to the costs of spare parts caused by the estimated influences, can be indicated as follows: Longer-term use of a vehicle earlier putting the vehicle into service in comparison with other vehicles; The replacement and use of significantly more expensive spare parts, which can be caused by the human factor, not by a hidden material trouble; The maintenance that is performed irresponsibly; The improper use of a vehicle or the training in extremely difficult conditions; The planned more demanding and more expensive maintenances or repairs; and Vehicle accident.

The PANDUR CZ vehicle was the subject of the research; the archival database of the PANDUR CZ armoured vehicle and the corresponding module of the Logistics Information System (LIS) have been used. The data of the spare part consumption from 2012 to 2017 has been analyzed.
Specifically, there are 7.5 thousand pieces of spare parts including 382 items. The normative of spare part consumption has also been examined.

\section{Analysis of spare part consumption}

When analysing spare part consumption, it is important to take into account whether the maintenance and repairs, during which spare parts were consumed, are planned activities or not. In operating the vehicles, all 3 types of technical maintenance (TM1, TM2 and TM3) are planned activities and a routine repair is a random activity [10]. In case of planned maintenance, the stocks of spare parts are managed using the pull system on the principle of dependent demand. In case of random repairs due to a failure rate or damage, the push system on the principle of independent demand should be used [11].

\subsection{Monitoring the economic demands of spare parts under consideration}

For a period of operating each vehicle included in the sample under consideration, the costs of spare parts have been spent since its putting into service by the end of 2017. The sample of vehicles used for research includes 67 PANDUR CZ vehicles operated by four different battalions (A, B, $C$ and $D)$ in the ACR. Vehicles are numbered 1-67. A synoptic table is not mentioned in the text of the article, but the graphical interpretation is shown in Figure 2. The vehicles numbered as $16,36,52,56$ and 59 show the most significant deviations. In the graph, they visually divide the costs into four sub-sections. 


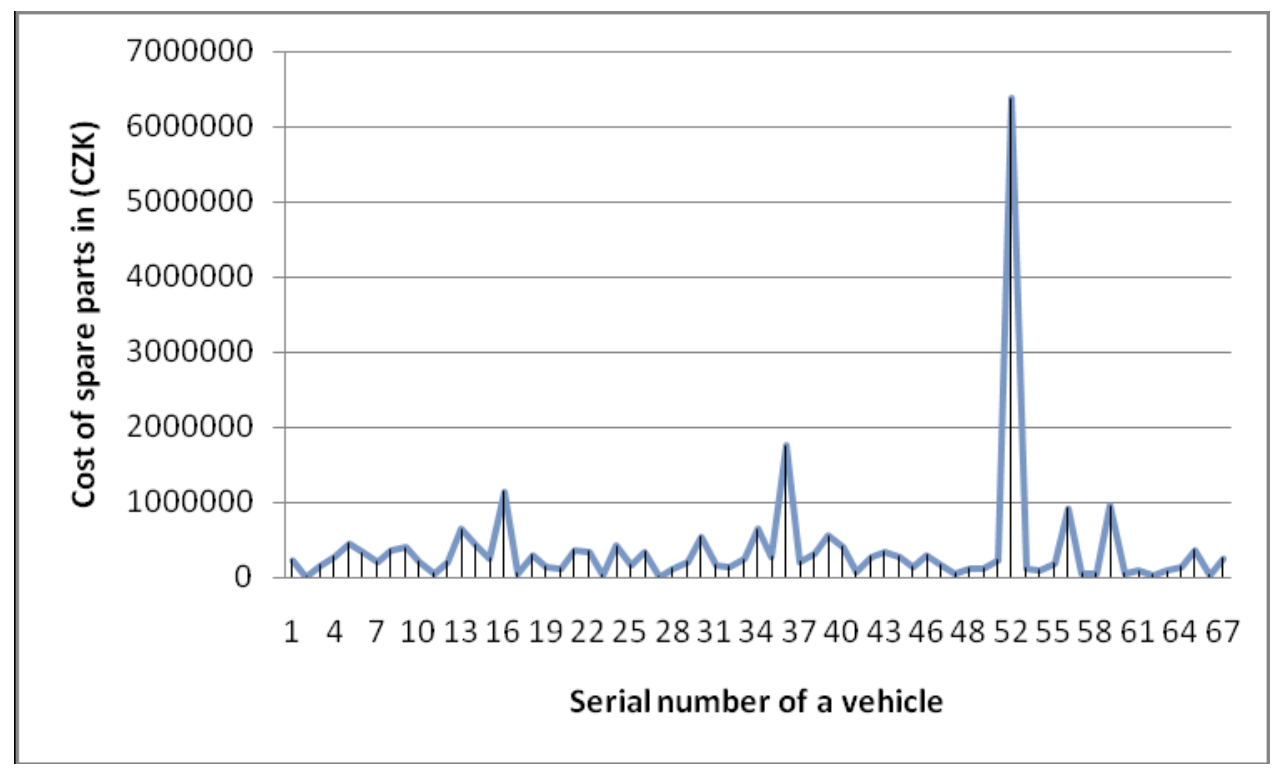

Figure 2 Overview of spare part costs for the sample of the PANDUR CZ vehicles

When considering the Logistics Information System (LIS) and graphic representation, there are some significant facts. It should be noticed why the spare part consumption of some vehicles strays from the common framework of consumption when compared with the others.

The PANDUR vehicle with serial number 16 is used in battalion A. The costs of spare parts amounted to $\mathrm{CZK} 1,144,747.77$ within the operating range from 2012 to 2018. For a given vehicle the maintenances marked as TM1 $2 \times$; TM2 $2 \times$ and routine repairs marked as RR $6 \times$ were implemented. In total, 84 items of different spare parts were consumed for a vehicle. The most expensive spare parts were: a wheel with a spare tire (CZK 157,492.24), a seal assembly (CZK 28,899.03), a tensioning cylinder diaphragm (CZK 14,188.36), an axle shock absorber (CZK 10,641.00), a left wheel drive (CZK 739,535.64), a spiral cable (CZK 13, 516.05), a spare tire (CZK 53,280.00) and a set of brake discs (CZK 20,315.04).

The PANDUR vehicle with serial number 36 is used in battalion B. The costs of spare parts amounted to CZK 1,755,273.99 in total within the operating range from 2012 to 2018. For a given vehicle the maintenances marked as TM1 $3 \times$; TM2 $3 \times$ and routine repairs marked as RR $9 \times$ were carried out. In total, 80 items of different spare parts were consumed for the vehicle. The most expensive spare parts were: a complete wheel with tire (CZK 157,492.24), the E6700.11 switch (CZK 27,315.75), gel accumulator (CZK $13,858.72)$, the EPAS28V/220A alternator (CZK 84,003.49), a set of seals (CZK 28,570.02), the paratroopers' space ramp (CZK 1,186,750.48), brake pads (CZK 28,077.17), gel accumulator (CZK 26,923.74) and a spare set (CZK 29,223.92).

Costs of spare parts for repairs of the vehicle with serial number 52 (Pandur) amounted to CZK 6,378,423.93 in battalion B. The vehicle was serviced and repaired with the following frequency: TM1 $3 \times$, TM2 $3 \times$ and routine repairs marked as RR $9 \times$ were implemented. In total, 26 items of different spare parts were consumed for the vehicle. The most expensive replacements of spare parts were: the CUMMINS ISC350 engine replacement (CZK 6,212,798.64), gel accumulator $(2 \times$ CZK 13,461.87), the TEPAS28V/220A alternator (CZK 85,153.82), brake pads (CZK 8,282.64) and brake disc with parts (CZK 13,461.87). 
Repair costs of the vehicle with serial number 56 (Pandur) amounted to $\mathrm{CZK}$ $930,030.55$ in battalion $C$. The vehicle was used from 2012 to 2017 . The vehicle was serviced and repaired with the following frequency: TM1 $1 \times$, TM2 $2 \times$ and RR $3 \times$. In total, 39 items of different spare parts were consumed. The most expensive replacements of spare parts were: $2 \times$ the NÁH.MSP100/1001 set (CZK 29,223.92), the CDU BVIS system (CZK 786,879.00), tire patch (CZK 7,469.64), etc.

Costs of spare parts for repairs of the vehicle with serial number 59 (Pandur) amounted to CZK 956,684.32 in battalion C. The vehicle was used from 2012 to 2017. The vehicle was serviced and repaired with the following frequency: TM1 $1 \times$, TM2 $1 \times$, TM $31 \times$ and RR $3 \times$. In total, 22 items of different spare parts were consumed. The most expensive replacements of spare parts were: a complete wheel with tire (CZK 157,492.24), a left wheel drive (CZK 737,316.72), a set of seals (CZK 23,198.31).

\subsection{The state of spare part consumption in the monitoring period}

The total spare part consumption in individual years from 2012 to 2017 for the sample of vehicles is illustrated in Table 2 . The spare part consumption is divided into individual maintenances and repairs. It is obvious that it is increasing due to the further use and, therefore, the wear of the material. The situation is also well illustrated in Figure 3.

Table 2 Overview of the total spare part consumption for the PANDUR CZ vehicles

\begin{tabular}{|c|c|c|c|c|c|c|c|}
\hline $\begin{array}{c}\text { Maint } \\
\text { type }\end{array}$ & $\mathbf{2 0 1 2}$ & $\mathbf{2 0 1 3}$ & $\mathbf{2 0 1 4}$ & $\mathbf{2 0 1 5}$ & $\mathbf{2 0 1 6}$ & $\mathbf{2 0 1 7}$ & $\begin{array}{c}\text { Total } \\
\text { maint }\end{array}$ \\
\hline RR & 92 & 140 & 105 & 166 & 826 & 733 & $\mathbf{2 , 0 6 2}$ \\
\hline TM 1 & 59 & 114 & 145 & 34 & 79 & 108 & $\mathbf{5 3 9}$ \\
\hline TM 2 & 103 & 343 & 237 & 252 & 573 & 94 & $\mathbf{1 , 6 0 2}$ \\
\hline TM 3 & - & & & & 958 & 2,246 & $\mathbf{3 , 2 0 4}$ \\
\hline Total & 254 & $\mathbf{5 9 7}$ & $\mathbf{4 8 7}$ & $\mathbf{4 5 2}$ & $\mathbf{2 , 4 3 6}$ & $\mathbf{3 , 1 8 1}$ & $\mathbf{7 , 4 0 7}$ \\
\hline
\end{tabular}

The situation is also well illustrated in Figure 3.

The increase in the consumption in the first two months of the year is caused by the purchase of spare parts at the end of the previous year. The rapid decrease in the spare part consumption is caused by the increased number of planned technical maintenances number 3 (TM3) in the $4^{\text {th }}$ and $5^{\text {th }}$ month.

The specified normative consumption of spare parts [12] enables the final storage of spare part items to be defined for individual planned technical maintenances and for individual organizational levels providing a given level and the type of repair services. Further, the abovementioned normative consumption defines the final storage of spare part items with low consumption in the Central Army Supply Depot.

The next step in analysing the consumption of spare parts is to compare it with the prescribed normative stocks of spare parts at the $1^{\text {st }}$ level, i.e. at the unit level. The consumption was evaluated and compared in the two battalions marked A and B for 2016 and 2017. During the monitoring period, both battalions consumed 4,138 pieces of spare parts in 175 items. Paradoxically, there is a different level of spare part consumption in individual battalions as well as their range of goods (see Table 3). There is no logically justifiable increase or decrease. 


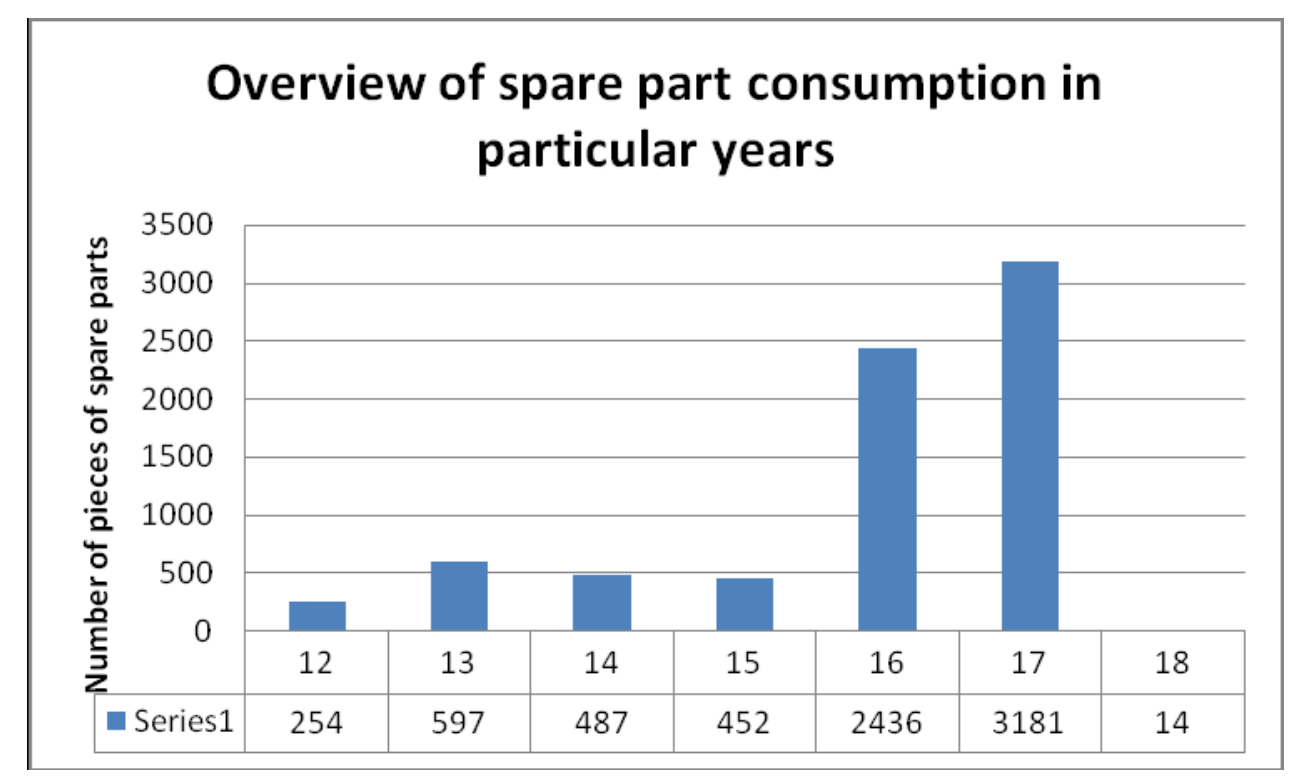

Figure 3 Overview of spare part consumption in monitoring years

Table 3 Overview of spare part consumption (source: LIS)

\begin{tabular}{|c|c|c|c|}
\hline In-year monitoring & Battalion & $\begin{array}{l}\text { Spare part } \\
\text { consumption [pcs] }\end{array}$ & Range of goods \\
\hline \multirow{2}{*}{2016} & A & 1,444 & 102 \\
\cline { 2 - 4 } & B & 271 & 41 \\
\hline \multirow{2}{*}{2017} & A & 949 & 100 \\
\cline { 2 - 4 } & B & 1,474 & 81 \\
\hline
\end{tabular}

4.3. Standard of consumption and its comparison with actual consumption

Only 19 items of spare parts were consumed identically in the abovementioned battalions in the monitoring period. A total of 19 selected items were compared with the determined normative, see Table 4.

The $\mathrm{x}$ letter in the column "NORMATIVE" means that the given spare part is not specified in the normative. The zero (0) symbol means that the spare part in the normative is set for another warehouse level. It is clear from the abovementioned data that it is necessary to pay attention to the normative and to correct this in the spirit of specified technological procedures for individual maintenances. The knowledge of statistics and MATLAB program has also been used.
The knowledge in relation to the normative and normative accommodation: in five cases it can be stated that the normative is sufficient; in four cases the normative is insufficient - it is undervalued. In seven cases the standard has not yet been established, it is necessary to determine it based on the current practice. In three cases, it has not yet been determined; it should be complied with in other units. 


\begin{tabular}{llccccc} 
S. & \multicolumn{1}{c}{ Name } & $\mathbf{1 6}$ & & $\mathbf{1 7}$ & & \\
N. & \multicolumn{1}{c}{ A } & B & $\mathbf{A}$ & $\mathbf{B}$ & NORMATIVE \\
1. & GEARBOX OIL CLEANER & 21 & 10 & 7 & 16 & $\mathrm{X}$ \\
2. & FUEL CLEANER & 31 & 13 & 24 & 33 & 12 \\
3. & BRAKE PADS BR.444F & 17 & 14 & 2 & 23 & 15 \\
4. & FILTER DCA4 - LARGE & 9 & 11 & 3 & 15 & $\mathrm{X}$ \\
5. & RADIATOR FILTER & 5 & 1 & 5 & 1 & $\mathrm{X}$ \\
6. & AIR COMPRESSOR HOSE & 6 & 3 & 1 & 1 & 0 \\
7. & PROPELLER SHAFT 1 A 2 NÁPRA & 2 & 3 & 1 & 1 & $\mathrm{X}$ \\
8. & PLAIN PIN & 20 & 11 & 23 & 22 & $\mathrm{X}$ \\
9. & BRAKE LININGS BR.456F & 106 & 24 & 44 & 45 & 0 \\
10. & V-BELT 6752012736 & 11 & 1 & 7 & 14 & 5 \\
11. & SEALING KOVOPLAST. SADA & 60 & 3 & 13 & 21 & 1 \\
12. & SEALING...VT-SADA & 112 & 7 & 7 & 12 & 2 \\
13. & HYDRAULICS CLEANING INSERT & 11 & 10 & 5 & 16 & $\mathrm{X}$ \\
14. & AIR FILTER ELEMENT & 24 & 20 & 14 & 34 & 23 \\
15. & FILTER INSERT & 11 & 10 & 7 & 16 & 0 \\
16. & FILTER ELEMENT & 12 & 11 & 8 & 17 & 23 \\
17. & AIR CONDITIONER FILTER & & & & & \\
18. ELEMENT & FUEL PRE-FILTER ELEMENT & 21 & 10 & 12 & 19 & 12 \\
19. & AIR DRIER ELEMENT & 19 & 13 & 19 & 18 & 23
\end{tabular}

\section{Conclusions}

The result of the examination was to assess the proposed process of optimizing the stocks of spare parts, whether it is fully operational and can be used in practice. It has appeared that increased attention should be paid to the assessment of spare part consumption. Their different level of consumption greatly affects the costs of training.

The extremely high consumption of brake lining in 2016 in battalion A may account for two reasons for increased consumption the increase in consumption may be caused due to an increased mileage and more intensive training or it is a case of unprofessional use of the vehicles in training, which should be alarming.
The statistical evaluation and the use of MATLAB indicate that the increase in spare part consumption is caused either by the aging of vehicles and by the lack of maintenance in terms or by the inconsistency in its implementation. This is due to the fact that the use of spare parts is different at the same maintenance levels.

Furthermore, an increase in the total cost ratio of spare parts in relation to the time of use of vehicles has been subsequently verified.

To determine the supply status and portable storage of spare parts for the PANDUR vehicle, the research will continue with the application of statistics resulting in a more precise proposal of the accommodation of standards.

\section{References}

[1] NSO (The NATO Standardization Office). AJP-4 Allied Joint Doctrine for Logistics. Edition B vision 1. Brussels, 2014. 
[2] MOD. Order of the Minister of Defense No. 54 from November 2017, Prague, 2017.

[3] MARES, Jaromir; KRÍZEK, Petr; ZAJICEK, Vaclav; HUSAK, Jan. The proposal to create provisions of land military equipment. The 23th International Conference. The Knowledge-Based Organization, Conference proceedings 2 Economical, Social and administrative Approaches. Sibiu, Romania: Publisching House, ALF, Sibiu, 2017, p. 83-89. ISSN 1843-682X.

[4] NSA (The NATO Standardization Agency). NATO System Life Cycle Processes - AAP-48. Standardization agreement. STANAG 4728. Edition B vision 1. Brussels, 2013.

[5] MOD. Teaching aids for ground military equipment. ČOS 051633. 2. Isue. Prague. 2017.

[6] MOD. Accompanying and operational documentation for military equipment and materials. ČOS 051632. 3. Isue. Prague. 2016.

[7] HLADÍK, T. TULACH, P. Effective maintenance of spare parts. [online] 2009 [cit. 12. 9. 2016] Available from: <http://archiv.logio.cz/wp-content/uploads/2009/11/ efektivni-rizeni-zasob-nahradnich-dilu-v-udrzbe.pdf $>$

[8] Logio, s.r.o. Optimization of stockpiles of materials and spare parts for maintenance Unipetrol. Case study. [online] 2015 [cit. 31. 1. 2017] Available from: $<$ https://logio.cz/unipetrol.html $>$

[9] ZIKMUND, M. Paretova (ABC) Analysis - a powerful tool in logistics, marketing and business [online] 2011 [cit. 31. 1. 2017] Available from: $<$ http://www.businessvize.cz/ rizeni-a-optimalizace/paretova-abc-analyza-mocny-nastroj-v-logistice-marketingu-iobchodu/pdf>

[10] MOD. Normative notification of the Ministry of Defense No. 5 from January 2018. Operation of ground military equipment in the Ministry of Defense. Prague, 201.

[11] LEGÁT, Václav. Logistics of spare parts and materials (NDM). Technical Faculty CU [online]. [cit. 2015-06-28]. Available from: <tf.czu.cz/ legat/Vyuka/ Servisni_Logistika/../14\%20Logistika\%20ND.ppt>

[12] MOD. Catalog - normative of spare parts for repairs of infantry combat vehicle „KBVPAnd armored armored transporters of all modifications carried out by troop means. Prague, 2010. Publ. No. 7301-0601-CZE-00. 